\title{
Por uma discussão ontológica e epistemológica dos ditos «Estudos Brasileiros» e algumas de suas consequências empíricas na França.
}

\author{
Márcia Marques Rambourg ${ }^{1}$
}

\section{Introdução}

\section{O que significa o termo «Estudos Brasileiros»? Que problemas, que métodos?}

Deve, a temática proposta para este artigo, ser avaliada sob tantos ângulos quanto forem possíveis. Trata-se de uma pergunta objetiva, que se impõe no significado do termo «estudos brasileiros» em uma perspectiva, assim, ontológica, que se deve, pela complexidade de sua aplicação, epistemológica.

Com efeito, vemos, aqui, a necessidade primeira - a fim de iniciar qualquer discussão acerca da teoria do conhecimento aplicada aos "estudos brasileiros" - de determinar os termos da proposição e de ver, neles, não somente o tratamento da área do conhecimento, mas sua essência; isto é, o que faz deste termo o que ele é e não outra coisa dele, diferente, ou, a ele, oposta.

Assim, para «estudos brasileiros», mesmo que se veja, de imediato e em aparência, a lógica da explicação, trata-se de determinar o que são, de indentificá-los, de compará-los e de distingui-los. Então, se não falamos de estudos germânicos, anglosaxões, espanhois ou, ainda, mesmo que igualmente lusófonos, de estudos portugueses, mas da produção intelectual de sujeitos interessados e engajados nos estudos que se denominam «brasileiros» - o que evoca oposições, similitudes, generalidades e particularidades - , faz-se mister determinar o que caracteriza tais estudos.

O que são, então, os estudos feitos em ou sobre o Brasil? Quais as áreas congêneres, pertinentes, periféricas, nucleares e essenciais que se mobilizam em torno

\footnotetext{
${ }^{1}$ ATER (Attachée Temporaire d'Enseignement et de Recherche), Université de Tours ; doutoranda em Estudos Brasileiros na Université Paris IV, Sorbonne. Membro do CRIMIC.
}

Brasiliana - Journal for Brazilian Studies. Vol. 1, n.1 (Sept. 2012). ISSN 2245-4373. 
da questão proposta, e que, sobretudo, suscitam o interesse e a pertinência da questão? Quais as motivações para este tipo de questionamento? Quais os problemas que surgem desta dinâmica? Pertinentes a tal questão seriam, então, todas as especulações feitas no campo das Humanidades relativas ao que se produz no domínio brasilianista, talvez não-somente no Brasil, mas, indubitavelemente, no exterior. E a problemática alargar-seia, tanto sob uma óptica interna dos trabalhos acadêmicos antropológicos, literários e sociais de brasileiros (ou de estrangeiros), em e/ou sobre o Brasil, como sob a perspectiva do trabalho acadêmico e/ou cultural acerca daquele país, fora dele. Vemos, aqui, dois olhares e duas ações, indubitavelmente - e ontologicamente -, bem distintas.

O termo "estudos brasileiros" pressupõe, assim, uma reflexão sobre a problemática da identidade, da repetição e/ou da diferença ${ }^{2}$ de ordem epistemológica emergente, com efeito, da perspectiva ontológica - , suscitando, igualmente, uma reflexão sobre problemas específicos, que, em se sobrepondo, em se adicionando a outros, em nâo se podendo, assim, apagar e anular os antecedentes, surgem reelaborados, em resposta a novas questões, numa estrutura de palimpsesto (genette) (categórica e empírica) a cada vez que se abordam e se produzem teorias sobre a «teoria do conhecimento». Tal problemática toca, evidentemente, todas as áreas humanas, e deve ser avaliada sob as perspectivas interna e externa, como vimos acima. Mas, quando estas perspectivas são, verdadeiramente, externas? E como se tornam internas? São, sem dúvida, externas quando se fala de estudos feitos «no exterior», em oposição aos estudos feitos no próprio país, e internas, quando, neste caso, produzem-se materiais intelectuais in loco.

\footnotetext{
${ }^{2}$ Pensamos, aqui, no conceito de "simulacro" na obra de Deleuze, Diferença e Repetição.Cf. DELEUZE, G. Différence et Répétition, Paris: PUF, 1969.
}

Brasiliana - Journal for Brazilian Studies. Vol. 1, n.1 (Sept. 2012). ISSN 2245-4373. 
Entretanto - e não é surpreendente dizê-lo - , os limites entre uma e outra dependem do ponto de vista, da necessidade de conhecer «de onde» emanam os discursos, mas, dependem, sobretudo, do efeito, da ação e da reação, de tais dinâmicas intelectuais. Com efeito, o que se discute quando se abordam os estudos brasileiros é justamente o que os estudos em torno do Brasil têm a sugerir como diferença e como novas perspectivas, novas estruturas do pensamento, tanto no nível de uma linha de pesquisa crítica "endógena", como naquele de uma visão exterior ao problema sugerido.

Surge, assim, uma problemática empírica de tais pesquisas, resultante das aplicações ontológicas e epistêmicas de tal comportamento científico. E como não se vêem ou se produzem os estudos brasileiros da mesma forma no Brasil e na Inglaterra, ou entre este país e um outro da Europa; ou, ainda, entre dois ou mais continentes, a visão (e a visibilidade!) da epistemologia dos estudos brasileiros, no exterior, repousaria, assim, mais em seu empirismo do que em sua essência. Empirismo este é, com efeito, guiado pelas estruturas internas de cada país receptor e produtor da cultura brasileira. Trata-se, aqui, de esferas quase «fractais» de recepção e de exploração da temática proposta: a estrutura externa (estudos brasileiros vistos e realizados fora do Brasil) cede o lugar à estrutura interna de cada país receptaculo, e tais estruturam dialogam e sobrepõem-se umas as outras.

O que nos interessa, particularmente para este artigo, é o amálgama destas questões na perspectiva dos estudos braileiros como noção ontológica dialética e, iguamente, na problemática literária dos estudos brasileiros, na França, ou seja, numa perspectiva externa de tais estudos, e que se torna interna pela própria idiossincrasia de organização e de recepção culturais. Como analisar, como discernir e determinar os estudos brasileiros, de uma perspectiva metafísica, primeiramente? Como questionar, 
em seguida, a aplicabilidade externa, e interna, dos estudos literários brasileiros no nível superior na França?

Não é questão, aqui, de discorrer sobre o progresso científico-pedagógico ou as vicissitudes dos mesmos em relação aos alunos, aos docentes do ensino médio, ou aos professores-pesquisadores universitários naquele país, mas de se questionar sobre como vemos e vivemos os estudos brasileiros (literários) no território francês sob os três ângulos que vimos de abordar: ontológico, epistemológico e empírico.

\section{Por uma discussão ontológica dos Estudos Brasileiros.}

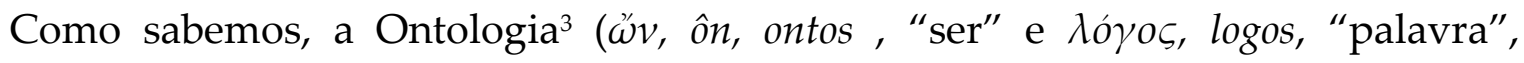
"discurso") é o ramo da Filosofia que se ocupa daquilo "que é" ou da essência de um objeto, de suas propriedades fundamentais, ou seja, de tudo aquilo que qualifica e que caracteriza um determinado objeto como sendo o próprio e não um outro. ${ }^{4}$

Dos pré-socráticos à filosofia moderna de Ricoeur e de Merleau-Ponty, por exemplo, observa-se o movimento do pensamento ontológico que conduz a uma filosofia moderna em que o homem será o centro da problemática e sua ação e relação com o mundo, objetos de novas correntes filosóficas.

Kant, em sua crítica teórica do termo inventado por ele (e retormado por Heidegger) de onto-teologia" que encontramos em sua Crítica da Razão Pura anuncia o

\footnotetext{
${ }^{3}$ Para nosso uso moderno, a partir de Kant e de Heidegger, o termo é "familiar", mas para os gregos, sobretudo para os pré-socráticos, a Ontologia, ou estudo do ser denominava-se Metafísica, ou Metafisica geral, a partir do século XVII, i.e., tudo aquilo que ultrapassa a Physikê, ou a Natureza. Paul Ricoeur introduz, influenciado, certamente, pela crítica racionalista de Kant, uma cisão completa entre a Ontologia e a Metafísica, esta sendo uma espécie de ontologia de fundo teológico racional e incompleta. Kant e Heidegger, antes de Ricoeur, também pressentiram e discorreram sobre o "fim da metafísica", no sentido de que a ontologia trata do ser como ser e não de uma ilusão metafísica tradicional.

${ }^{4}$ Segundo o conhecido vocabulário de Parmênides, "fundador", por sua vez, antes de Aristóteles, da Metafísica, tal qual se conhecia antes do termo moderno de Ontologia.
}

Brasiliana - Journal for Brazilian Studies. Vol. 1, n.1 (Sept. 2012). ISSN 2245-4373. 
nascimento de uma filosofia ontológica livre, em que o estudo do ser, de suas características e de suas ações no mundo, bem como sua perspectiva de causalidade, sob a égide da racionalidade, distingue-se e destaca-se do cânon da Teologia. Não é, assim, surpreendente que Martin Heidegger, no século XX, discípulo de Husserl e sensível aos preceitos da Fenomenologia deste último, introduza, na linha crítica racionalista kantiana, uma nova determinação de uma ontologia (mesmo que a digamos mais política do que metafísica) da existência do homem: "o ser é; o homem existe". ${ }^{5}$

Mais à frente, e tocando diretamente nosso estudo apresentado para este artigo, Emmanuel Levinas introduz na França (país onde vive a partir de 1923) a fenomenologia de Husserl (que ele traduz para o francês) e de Heidegger. Sensível ao "desumano do humano", ao rosto que desnaturaliza o natural do ser, e, ao mesmo tempo que explora a eticidade do sujeito observador, Levinas fará de sua ontologia, uma ontologia à parte.

A alteridade, sendo a base de sua teoria filosófica, dará à filosofia moderna não somente uma vertente possível de discussão da alteridade em face do Eu, mas do Eu em face do potente, infinito (do ponto de visto cartesiano) e inatingível Outro. Tal perspectiva filosófica, longe de determinar categoricamente uma fenomenologia estanque da alteridade, sugere, ao contrário, uma relação com o outro que introduz tanto a eticidade do sujeito em relação à noção, mesmo, de ética, como a noção de presença na ausência, ou de fertilidade no vazio: o Outro é somente o outro naquilo que ele não é. Entramos, aqui, em contato e em ação com outro sujeito quando, nele, encontramos o infinito palpável, sendo, o rosto, a metonímia da nudez e da transparência inatingível do Outro.

\footnotetext{
${ }^{5}$ Cabe lembrar que a Ontologia a partir de Kant, passa a se preocupar, cada vez mais, não somente com a problemática do ser, mas do ser «humano», associando-se, com todo evidência, à Fenomenologia.
}

Brasiliana - Journal for Brazilian Studies. Vol. 1, n.1 (Sept. 2012). ISSN 2245-4373. 
Em outros termos, se o corpo para Espinoza ${ }^{6}$ estabelece as relações ontológicas fundamentais com o mundo, o rosto, para Levinas, será um conceito, um suporte nãofísico, evidentemente essencial do ponto de vista fenomenológico, mas um espaço da possibilidade do impossível, da visão de uma esfera impossível de definir ou de identificar, mas que, por isto mesmo, será a esfera da possibilidade da existência de um Outro, diferente de mim e eticamente presente em mim. A alteridade é, assim, para Levinas, tanto um espaço ético subjetivo, como um espaço do desejo de preenchimento da ausência (infinita) do Outro em que “o Desejo metafísico do absolutamente Outro satisfaz-se à medida que este não o é". ${ }^{7}$

Se estas rápidas linhas acerca da perspectiva filosófica ontológica levinasiana interessa-nos é porque elas nos permite ver, de maneira diacrônica que, para que se discuta a aplicação dos estudos brasileiros, e, para esta secção, os estudos brasileiros literários, na França, enfim, para que se tente vislumbrá-los sob uma óptica externa, mesmo em movimento interno e em perpétua abertura, embora tal corrente filosófica nos conduza a uma elevação discutível de alteridade na questão do Tout Autre e do TrèsHaut, ela parece-nos ser a mais pertinente no sentido de que a alteridade seria, aqui, o princípio fundador da problemática metafísica dos Estudos Brasileiros vistos e percebidos $^{8}$ "de longe".

Sem nos atermos, por hora, ao fato francês, ou nos retermos a elocubrações para explicarmos o "princípio fundador" dos Estudos Brasileiros, seria interessante pensar na causa primeira, na base epistemológica (e, aqui, antes, ontológica) de modelos de

\footnotetext{
${ }^{6}$ A questão proposta por Espinoza, em seu livro Ética: «Quid Corpus possit» evoca o ratio ou uma relação de movimento.

${ }^{7}$ Em francês, «Le Désir métaphysique de l'absolument Autre est satisfait dans la mesure où il ne l'est pas.» Tradução minha. Cf. LEVINAS, Emmanuel. Totalité et infini. Essais sur l'extériorité. Nijhoff, La Haye, 1961

${ }^{8}$ Fala-se, aqui, do verbo «perceber » em sua concepção fenomenológica.
} 
pensamento novos, da qual resultam as mais diversificadas consequências empíricas, de que trataremos mais adiante. Seria, assim, pertinente, pensar na estrutura ontológica dialética do modelo de pensamento dos Estudos Brasileiros, e determinar as consequências diretas de tal aplicação teórica.

Aqui, quando abordamos uma "causa primária" dos Estudos Brasileiros, falamos, essencialmente, da alteridade em face de modelos novos. A partir de quando os modelos ontológicos dos Estudos Brasileiros se podem formar? E como tal formação se observa?

Trata-se, aqui, de modelos de pensamento que repousam na dinâmica de abertura de si, ou do Mesmo em direção ao Outro. Falamos de "Estudos Brasileiros", com letras maiúsculas, o que nos permite pensar em uma disciplina per se; uma disciplina que abarca um método e uma dinâmica próprios, uma construção idiossincrática e, enfim, uma recepção e uma dialética que fazem dela o que ela é e não outra "coisa".

Falamos, assim, do trabalho (isto é, da energia e da aplicação de ideias) do que são tais estudos, da afirmação dos mesmos, da caracterização do trabalho intelectual sobre o Brasil não-somente, talvez, dentro de uma dinâmica do être, ou daquilo "que é", daquilo que o distingue do que "não-é", mas sob uma óptica de abertura, uma estrutura do étant, do devir, da distância (mas, sobretudo, do espaço fértil desta distância) entre dois pontos principais, entre o Mesmo e o Outro.

Ora, questionar sobre quando e como se formou, precipuamente, um modelo metafísico dos Estudos Brasileiros seria questionar o Outro, um Outro anterior, e o que há por vir; e construir, por conseguinte, e por analogia, uma estrutura dialética. A questão é absolutamente pertinente, sobretudo quando se trata da problemática de um modelo epistêmico exterior ao que se lhe destina e ao que se designa. Diferentes são, desta forma, os modelos interno e externo do que se vê como estudos do conhecimento brasilianista dentro e fora do Brasil.

Brasiliana - Journal for Brazilian Studies. Vol. 1, n.1 (Sept. 2012). ISSN 2245-4373. 
Um modelo (ou uma noção) existe somente quando relacionado(a) aos modelos ou às noções precedentes. Estamos, assim, numa perspectiva ontológica estritamente relacional quando tratamos de uma "causa filosófica" da disciplina que podemos chamar, autenticamente, de "Estudos Brasileiros". O que veio "antes" ou o que virá "depois", como material ontológico, da noção que abordamos determina a própria noção, mas a questão da temporalidade (e pensamos na teoria bergsoniana e jankelevitchiana de tempo e de ação $)^{9}$ faz parte deste raciocínio do Outro, já que lhe dá o aspecto espacial e determina a ação do sujeito numa nova esfera espácio-temporal. É , portanto, essencial pensar na sincronia e na diacronia das ações de uma área do conhecimento, e sobretudo, pensá-las na estrutura de movimento, ou de transição, em direção ao novo.

Assim, não é por oposição ao que não é do domínio das Humanidades brasileiras, como qualquer outro campo existente, não-brasileiro, que teremos uma visão ontológica pertinente de tais estudos: é na relação que existe entre tais espaços de articulação do saber que suas essências poderão existir. Relação interna e externa da mesma noção. A antropologia de Gilberto Velho, por exemplo, estudada no Brasil terá uma estrutura interna visando ao espaço do Outro, num horizon d'attente ${ }^{10}$ específico em que a massa de recepção poderá convergir para dentro do espaço brasileiro e, evidentemente, para fora dele, pela articulação natural do conhecimento. Mas, a mesma especulação teórica antropológica feita fora do Brasil abraçará não-somente a dinâmica externa e interna, categórica e esperada em toda problemática que se introduz concernente ao Brasil, mas apontará, sobretudo, para "o que não está", para a perpétua "ausência da presença" que

${ }^{9}$ Cf. Bergson, Henri. Matière et Mémoire, Paris : PUF, 1965 ; e La pensée et le mouvant. Paris: Les Presses universitaires de France, 1969, 294 pages. Collection Bibliothèque de philosophie contemporaine. Em relação à filosofia de Jankélévitch, é interessante ver Le Je-ne-sais-quoi et le presque-rien, Paris, PUF, 216 p.

${ }^{10}$ Referimo-nos à noção de horizonte de expectativa do leitor, conceito que nasce na teoria da recepção de R. Jauss, retomado por W Iser e A. Compagnon.

Brasiliana - Journal for Brazilian Studies. Vol. 1, n.1 (Sept. 2012). ISSN 2245-4373. 
fará com que o espaço de investigação se abra e se reconstrua ad infinitum na tentativa infinda de percepção e reconhecimento do Outro, mas de um duplo Outro, estrangeiro.

À imagem poética de Édouard Glissant, no livro Pays rêvé, Pays réel:

“L'Étant nubile dévole au feu ses îles

L'Être se boute aux proues de terre, il commande (...)"11

Temos a sensação de que a relação, ou a Relação ${ }^{12}$, das coisas no mundo faz-se mais pelo movimento e pela abertura das mesmas do que por sua determinação dogmática, como, por exemplo, na perspectiva heideggeriana do être e do étant.

Esta passagem do poema do autor de Tout-Monde - em que se observa, numa perspectiva ontológica de abertura, a aproximação da multiplicidade e da possibilidade da presença das ilhas ao étant, e em que se estabelece a restrição e a imposição à noção de être - corrobora, assim, a ideia de que o mecanismo de reconhecimento e de identificação de uma cultura dá-se, efetivamente - com o risco de nos repetir - pelo viéis metafísico dialógico da diferença, da similitude, da aproximação, e da distância.

Podemos dizer que a formação ontológica dos Estudos Brasileiros como disciplina deve-se à natureza e à estrutura de formação entre disciplinas humanistas congêneres. E, dentro da dimensão relacional de alteridade de que tratamos acima, o "sendo" - ou o "devir" - corrobora a tensão interna de uma e outra áreas do conhecimento. É, portanto, no reconhecimento e no estranhamento do Outro que o Mesmo se constroi. Há, aqui, a partir da abordagem ontológica levinasiana, a

\footnotetext{
${ }^{11}$ Glissant, É. Pays rêvé, pays réel. Paris: Gallimard, 2000.

${ }^{12}$ Ver, aqui, o conceito dialético de Relação tal como imaginou Glissant, em Poétique de la relation. (Poétique III) Paris: Gallimard, 1990.
}

Brasiliana - Journal for Brazilian Studies. Vol. 1, n.1 (Sept. 2012). ISSN 2245-4373. 
constituição de elementos intrínsecos ao que chamamos "Estudos Brasileiros", e que se formarão, impreterivelmente, na tensão entre o ser e o devir, uma óptica de formação interna, forçosamente, entre todas as áreas do conhecimento. A Literatura abraçaria a Filosofia, que o faria com a Antropologia, esta com a Linguística, e assim por diante, numa estrutura de ligação e de separação que fariam delas as disciplinas que existem por identificação e diferença.

Já a formação ontológica dos Estudos Brasileiros como disciplina externa - e estrangeira - i.e., como modelo de execução semiótica de dupla abertura, sofreria outro tipo de ação, ou de transformação ontológica. O modelo epistemológico que "fertiliza" o campo de uma disciplina estrangeira em um espaço outro (e do Outro) repousa sobretudo da necessidade epistemológica da sua aplicação, em si, e logo no empirismo de como existem e o que devem ser, na verdade, tais estudos.

Assim, os Estudos Brasileiros, em sua óptica de abertura à dialética e à renovação - sobretudo porque eles são, em essência, o "Outro do Outro" quando não são produzidos no Brasil - , não podem fugir à regra da ontologia dialética, mas o essencialmente Outro, o infinitamente desejável e inatingível que não sou Eu, e não se pode apreender por Mim, convida-me a pensar na perspectiva dos Estudos Brasileiros na formação de esferas (de rostos levinasianos) que se tornam possíveis na dinâmica fenomenológica da formação externa-interna dos mundos.

No caso, portanto, de sugerir uma proposta de estudo ontológico, primeiramente, e epistêmico, em seguida, dos estudos feitos sobre o Brasil, no exterior, vemos que o movimento externo-interno-externo nessa dinâmica de observação, percepção e reprodução induz ao estudo do ser, para, em seguida, pensarmos na perspectiva da teoria do conhecimento e em sua realidade empírica.

Brasiliana - Journal for Brazilian Studies. Vol. 1, n.1 (Sept. 2012). ISSN 2245-4373. 


\section{A perspectiva epistêmica dos estudos literários brasileiros, na França, e sua aplicabilidade empírica.}

A Literatura enquadra-se, por si mesma, formalmente, na alteridade. Se se citam todos os principais críticos teóricos da Literatura, de Homero a Platão, de Valéry a Todorov, de Jauss, Jakobson, a Compagnon, passando, assim, pelo estruturalismo até ao New Criticism e à teoria da recepção, as correntes críticas acordar-se-iam ao fato de que a Literatura - ou, mais precisamente, a Poïética (a técnica - do grego, $\tau \hat{\varepsilon} \chi v \eta$ - do logos, poiêtikês) - é a arte, precípua, de transformar o Real.

Mas, metaforizar a Realidade, dar-lhe os contornos do estilo, dar-lhe recepção, criação e re-criação; dar-lhe, enfim, o desenho do quadro, os níveis de visão e de percepção é dar-lhe fenômenos e imagens, imaginários; é, portanto, pintar a realidade extra-linguística para oferecê-la ao Outro, para dar a ver ${ }^{13}$ ao Outro o que se não pode ver, e o que se poderá ver.

O texto literário não se escreve, assim, sem que se percorram espaços vazios e que se preencham com a presença do Outro; em direção a algum ponto longe do Eu, mas, talvez, justamente, para deste aproximar-se; em direção, enfim, a algum ponto imaginário em que outras esferas serão possíveis. E nesta dimensão essencialmente ambivalente da Literatura, a dinâmica de abertura une-se, então, naturalmente, àquela da alteridade.

Falávamos da dimensão externa dos Estudos Brasileiros, de sua perspectiva metafísica exógena produtora de sentido, aberta à ação de preenchimento espacial

\footnotetext{
${ }^{13}$ Retomamos a ideia poética (ou o trabalho poético) bastante conhecido de João Cabral de Melo Neto, quando, em sua concepção de fenômeno poético, prefere o concreto ao abstrato, o simples ao complexo, o «dar a ver» ou - o visual «transitivo» - ao musical.
}

Brasiliana - Journal for Brazilian Studies. Vol. 1, n.1 (Sept. 2012). ISSN 2245-4373. 
através da leitura, da recepção, da difusão do material intelectual, em que a noção de transitividade torna-se essencial. Tal perspectiva externa dos Estudos Brasileiros, e em se tratanto dos estudos literários feitos fora do Brasil, ganha uma outra dimensão: aquela da aplicação empírica da problemática aqui exposta. Se, em termos gerais, pudemos definir, grosso modo, o que seriam os "Estudos Brasileiros" dentro, em linhas gerais, da perspectiva ontológica levinasiana, em que o desejo do outro enquadra-se numa dinâmica de exteriorização-interiorização do Mesmo, a perspectiva os estudos literários percebidos e produzidos no exterior serão, por sua vez, aplicados à discussão de uma ruptura do cânone epistemológico.

Concretamente, no caso da França, há dois ângulos possíveis de problema epistemológico, que nos conduzem, imediatemente, àquele empírico, dos estudos literários brasileiros.

O primeiro trata, efetivamente, do escopo externo que abordamos mais acima, i.e., da problemática de alteridade em que o Outro observa, de longe, um "outro Outro", e tenta, à distância, apreender-lhe os meandros da percepção. Este escopo externo apresenta, imediatamente, o que Bachelard chama de "obstacle épistémologique"14: a dificuldade científica da pesquisa intelectual; a escuridão na busca da luz do conhecimento, aquilo que advém da ignorância da opinião e que se deve encaixar na clareza da ciência.

O conhecimento, segundo Bachelard, não existe jamais ex nihilo: ele é a busca incessante da essência do objeto, já que "toda cultura científica deve começar (...) por uma catarsis intelectual e afetiva. Resta-nos, em seguida, a tarefa mais difícil: pôr a cultura científica em estado de mobilização permanente, substituir o saber fechado e

\footnotetext{
${ }^{14}$ BACHELARD, G. La formation de l'esprit scientifique. Paris : J. Vrin, 1938, 216 p.
}

Brasiliana - Journal for Brazilian Studies. Vol. 1, n.1 (Sept. 2012). ISSN 2245-4373. 
estático por um conhecimento aberto e dinâmico, dialetizar todas as variantes experimentais, dar, enfim, à razão, razões para evoluir". ${ }^{15}$

A exigência epistemológica da prática intelectual dos estudos literários brasileiros no exterior e, particularmente, no caso da pesquisa acadêmica francesa nos remete, talvez, à ideia bachelardiana da necessidade de ruptura de modelos fechados, em prol de uma nova organização epistêmica. Não é, entretanto, o "mal-estar" intelectual, o primeiro passo para o re-conhecimento do objeto, mesmo que, em sua honestidade no tratamento da dificuldade científica, seria interessante entrever o problema do escopo externo de ação da Literatura Brasileira, na França , mas, sobretudo, a noção de obstacle épistémologique - tal qual pensou Bachelard - no que esta tem de ruptura conceitual, ou no movimento de uma crítica científica de ruptura de modelos epistêmicos existentes.

O primeiro problema de que se trata, aqui, refere-se, assim, ao tratamento científico dos estudos literários brasileiros. Não se discutem a qualidade ou o rigor das pesquisas acadêmicas cuja temática são os estudos brasileiros, evidentemente, já que demonstram, indubitavelemente, níveis conceituais complexos e fecundos. Não se discute, ainda menos, o nível de exigência acadêmica para o desenvolvimento de tais pesquisas, o problema aqui proposto repousa na dinâmica de transformação, de renovação e de revitalização dos estudos literários brasileiros feitos na França.

Este primeiro problema, que trata da dinâmica externa da pesquisa literária brasileira no espaço intelectual interno acadêmico francês, procura, assim, estabelecer a análise do espírito crítico de tal disciplina, no âmbito da observação externa. É a busca do objeto científico em vistas à sua aplicabilidade que nos interessa. Depois que determinamos o que são - ou que poderiam ser - os "Estudos Brasileiros" sob a perspectiva da alteridade, seria interessante, em seguida, determinar a aplicação da

\footnotetext{
${ }^{15}$ Ib idem, p.21
}

Brasiliana - Journal for Brazilian Studies. Vol. 1, n.1 (Sept. 2012). ISSN 2245-4373. 
ontologia discutida nos mesmos, ou seja, ver, neles, um objeto a ser tratado; e se tal questão se impõe, estaremos diante de um problema intrínseco à teoria do conhecimento.

Com efeito, o primeiro obstáculo epistemológico que evoca consequências empirícas diretas, como dissemos, repousa sobretudo na recepção da Literatura Brasileira na França. Problema literário que tem sua primeira causa não-somente na falha - ou no desinteresse, por grande parte - mercadológico editorial das literaturas de língua estrangeira da África e da América do Sul, com frutíferas exceções, como Acte Sud e as Éditions Métailié (esta última consagrando sua publicação aos grandes nomes da Literatura Brasileira moderna e contemporânea), mas na articulação dos saberes humanistas ligados à área literária brasileira.

Estamos, assim, em face, novamente, do problema da alteridade levinasiana (o Outro, o Tout-Autre, superpotente, inatingível) que abordamos mais acima, e, igualmente, numa dinâmica relacional dialética ontológica heideggeriana (o étant é próprio do homem, do être-dans-le-monde, já que este se refaz em sua existência $\left.{ }^{16}\right)$, que nos conduz ao problema epistêmico (examinar a Literatura Brasileira como conhecimento) e empírico (examinar a Literatura Brasilera como aplicação do conhecimento, ou das ideias ) da Relação.

Ler a Literatura Brasileira, relacioná-la com outras áreas do conhecimento; dispor de meios para percebê-la, recebê-la e apreendê-la na relação que ela engaja com outros domínios humanistas quer dizer mobilizar todos os meios epistemológicos para identificar o que são os estudos literários brasileiros, e em seguida, problematizá-los na teia empírica. O que queremos dizer, simplesmente, é que não se pode querer analisar

\footnotetext{
${ }^{16}$ Cf. explicação dada por Emmanuel Levinas sobre o Dasein (être-là) e o de Daseineles (l'étant-là heideggerianos, em En découvrant l'existence avec Husserl et Heidegger. Paris: Vrin, 2001. 336 p
}

Brasiliana - Journal for Brazilian Studies. Vol. 1, n.1 (Sept. 2012). ISSN 2245-4373. 
nem os Estudos Brasileiros, tampouco os estudos literários brasileiros, sob uma óptica epistemológica sem, para que esta última funcione como problema filosófico, vislumbrar, antes, sua ontologia dialética e, finalmente, sua aplicação empiríca. Estes três ramos filosóficos estão intrinsicamente ligados, sobretudo quando se vêem as relações da Literatura Brasileira no exterior.

Problematizando, assim, as Letras Brasileiras no exterior, na teia empírica, temos o problema da divisão do espaço intelectual. Sem a pretensão de definir, aqui, a noção de "espaço" ou de "espaço intelectual", vejamos somente que tal termo, como problema na aplicação epistemológica, encontra, em seu bojo, o enfraquecimento da ação do pensamento intelectual humanista e desestrutura a teia fenomenológica dos estudos brasileiros no ponto de vista da produção externa.

Há inúmeras possibilidades (e argumentos) que poderíamos discutir aqui nesta secção, mas nos parece primordial entrever a ação do material intelectual feito sobre o Brasil sob o ângulo da recepção e da relação.

Existe como uma paisagem, aberta e dialética, quando se fala de estudos estrangeiros. Em qualquer lugar, em qualquer esfera exterior ao discurso original, falase da percepção do objeto estrangeiro, exotérico, pronto para ser consumido e entendido em sua essência. Os Estudos Brasileiros, na França, não fogem a essa regra de "alterofagia" fértil e ambivalente, e se consomem como objeto do Outro, que não integrará o Mesmo, mas o reformulará através do intercâmbio semiótico-cultural.

Entretanto, o espaço de partilha ideológica vai depender do mecanismo interno de recepção de cada exocultura e este mecanismo, idiossincrático, porquanto faz parte da formação interna de cada país, deverá ser um mecanismo de fenômenos. E fenômenos "em direção ao concreto", ${ }^{17}$ à experiência das ideias em uma relação.

\footnotetext{
${ }^{17}$ Sobre William James, cf. Wahl, Jean André. Vers le concret, Vrin, 1932; rééd. Avant propos de Mathias Girel, Paris: Vrin.
}

Brasiliana - Journal for Brazilian Studies. Vol. 1, n.1 (Sept. 2012). ISSN 2245-4373. 
Assim, o obstáculo que vemos aqui se dá na articulação epistemológica entre as Humanidades. A fórmula empírica de William James ("at their face value") ${ }^{18}$ que nos remete à simplicidade ou ao pragmatismo das ideias e das "coisas" nelas mesmas nos faz pensar à aplicação de cada área do conhecimento dos Estudos Brasileiros, no exterior, e chegar à conclusão de que, mesmo que estejamos em face do valor pragmático de cada campo das ideias, tais valores poder-se-iam comunicar mais, e a aplicabilidade dos estudos - em particular, literários - deixar as zonas de sombra de trabalhos intelectuais sem articulação interna.

O fundo do problema empírico que toca os etudos literários brasileiros repousa, enfim, não na especificidade (que é necessária a cada área do conhecimento, e sua respectiva ação ideológica isolada para que seu sistema interno funcione), mas, talvez, numa lacuna na coesão interna entre as áreas humanistas, que deveriam, por fazerem parte, justamente, do escopo dos estudos brasileiros no exterior, evocar um bloco maior de diálogos e de trocas intelectuais mais uníssonas. Entenda-se que não se discutem a legitimidade e o campo de ação das várias áreas humanistas no espectro epistêmico francês, como comprovam os inúmeros departamentos de civilização e cultura brasileiras em entidades superiores, mas a ação dialética e relacional que tais áreas poderiam intensificar no diálogo literário numa perspectiva comum.

O segundo problema ou obstáculo epistemológico que nos parece essencial à crítica da aplicação empírica na recepção dos estudos literários brasileiros na França repousa mais na cracterização do que é (ou do que "pode" ser) a Literatura Brasileira naquele país (trata-se dum ramo da literatura feita na América Latina, trata-se da literatura que fala do Brasil, que se importa do Brasil...?) do que a problemática da

\footnotetext{
18 "At their face value" é a expressão de William James fala das coisas como elas são, como elas se revelam por si mesmas. Ib idem, p.31
}

Brasiliana - Journal for Brazilian Studies. Vol. 1, n.1 (Sept. 2012). ISSN 2245-4373. 
difusão da língua portuguesa como idioma estrangeiro, base semiótica, indubitavelmente, essencial para a apreensão da literatura de expressão portuguesa.

Há, evidentemente, nesta última questão, um fator de desaceleração linguística fato, por muitos, observados, tal como o enfraquecimento do ensino do português na França, ou a ausência de concursos públicos de docentes de português no nível médio mas tal aspecto é um problema sócio-econômico e histórico que revisita a questão do prestígio linguístico da língua portuguesa na França e todos os complexos movimentos culturais de migração populacional e de troca cultural ligados à implantação e ao desenvolvimento da língua portuguesa há mais de meio século.

Não é, entretanto, a desaceleração do ensino do português - mesmo que esta seja uma real problemática em si - o problema epistemológico central que abordamos neste artigo, mas a difusão do que é a Literatura Brasileira. De um "o que é" aplicado, analisado, contextualizado; empírico.

Tornamos, desta maneira, a tratar da questão ontológica e epistemológica dos estudos brasileiros no exterior para chegarmos à aplicação de suas Ideias, ou de suas Sensações. Trata-se de tentar "preencher um vazio", uma noção, um movimento do espírito, como à imagem da tabula rasa lockiana ${ }^{19}$.

Não é que o espaço da recepção literária brasileira na França encontra-se "vago", longe disto, mas é que as estruturas que o levam ao preenchimento são ainda estruturas

\footnotetext{
${ }^{19}$ Locke nos convida a imaginar o preenchimento da tabula rasa, que é propriamente o espírito humano, através da experiência espiritual interior (ou a reflexão) e exterior (sensação): «(...) Suponhamos, então, que, no começo, a Alma seja o que chamamos de Tábula Rasa, esvaziada de todas as suas caracteística, sem nenhuma ideia, qualquer que seja. Como, então, ela recebe as ideias? Por que meios ela adquire esta quantidade que é a imaginação do Homem, sempre em ação e sem limites, que lhe apresenta com uma variedade quase infinita ? Donde ela esgota todos os materiais que se formam como fundo de todo raciocínio e de todo conhecimento? A isto, eu respondo em uma palavra : da Experiência. (...) Mas, como eu chamo a outra fonte de nossas ideias «Sensação», nominarei esta última, «Reflexão», porque a alma só recebe as ideias que ela recebe em refletindo sobre suas próprias operações. É por isso que vos peço obsevar que (...) entendo, por «Reflexão», o conhecimento que a alma adquire a partir de suas diferentes operações, através das quais, o conhecimento vem a se formar de ideias» Tradução minha. Locke, Essai concernant l'entendement humain, Paris: Vrin, 1989, 627p.
}

Brasiliana - Journal for Brazilian Studies. Vol. 1, n.1 (Sept. 2012). ISSN 2245-4373. 
em formação identitárias. São estruturas "sensíveis" e fortemente móveis na dinâmica de formação de mundos, ou de fabricação de fatos, para tomar, como exemplo, o vocabulário de Nelson Goodman ${ }^{20}$. Estamos, assim, diante duma fenomenologia da percepção, em que a experiência da recepção literária determinará o processo de preenchimento de sentido do texto brasileiro, numa perspectiva fenomenológica ligada à identidade cultural, à caracterização "pragmática" do que seriam, para os franceses, primeiramente, o texto brasileiro, em seguida, os estudos literários brasileiros, de maneira ampla e categórica.

Ora, a experiência poética é, por si mesma, uma experiência de preenchimento semiótico. O estudo da Sensação - noção-chave para entendermos a teoria empírica fenomenológica que pode partir de "ideias" simples ("sinto o vermelho, o azul, o quente, o frio"21) - é, grosso modo, o estudo do fenômeno da consciência individual, que é consciência objetiva, aquela que absorve os fatos do mundo, suas cores, suas formas, suas nuances, seus sujeitos, suas identidades e transforma-o em novas esferas do entendimento.

A sensação na poesia é, por sua própria lógica interna, uma noção de identidade. Uma noção que, "determinando com os olhos" e "definindo pelo sentido" 22, indica a direção ontológica, pura, do objeto que queremos definir e "compõe todo o conhecimento de qualidades determinadas e constroi-nos objetos limpos, puros,

\footnotetext{
${ }^{20}$ Goodman, Nelson. Ways of wordlmaking (Manière de faire les mondes). Trad. Marie-Dominique Polelard. Paris: Folio Essais, p. 131

${ }^{21}$ Merleau-Ponty, Maurice. Phénoménologie de la perception. Paris: «Tel» Gallimard, 1945, chap. I, «La «sensation», p. 25

${ }^{22}$ Id idem, p. 29
}

Brasiliana - Journal for Brazilian Studies. Vol. 1, n.1 (Sept. 2012). ISSN 2245-4373. 
absolutos que são, essencialmente, o ideal de consciência (...) e que se adapta somente à superestrutura tardia da consciência". ${ }^{23}$

Essa noção de objetivação da teoria da sensação, tal como entendemos na filosofia de Merleau-Ponty, engaja-se na dinâmica da identificação da Literatura Brasileira como realidade objetiva que se pode ver e sentir, e, logo, apreender, como o que ela é ou deve ser.

Trocando em miúdos, se aqui se discute a identidade nascente dos estudos brasileiros na França é porque a visibilidade ("vemos somente aquilo que não se nos apresenta"24) dos mesmos ainda não se dá na estrutura de sua apreensão ideológica. Precisamos "não ver" o texto, i.e., ver o que o texto deixa "por ver", seus espaços incompletos, seus meandros imaginários, ter a Ideia ou a Sensação do texto, para determinar, no vazio fértil da experiência da leitura, o que podem ser a criação e a produção da poética brasileira.

Evidentemente, essa questão não se faz exclusiva do contexto francês, ou do contexto dos estudos brasileiros no exterior, sendo pertinente, sem dúvida, a qualquer contexto de recepção litéraria que exista. Mas, a experiência do texto literário brasileiro no escopo de visão de uma realidade "Outra" deve ser aquele da construção (como, aliás, em qualquer texto), mas sobretudo uma construção cultural de identidade exógena na percepção empírica do que "pode ser" ou que que "vem a ser" brasileiro no domínio textual.

Talvez ainda não estejamos nesta esfera da visão fenomenológica das categorias essenciais que interessem à formação identitária da Literatura Brasileira, no exterior, mas talvez a difusão da mesma se possa fazer na discussão empírica dos problemas

\footnotetext{
${ }^{23}$ Ib idem, p. 34

${ }^{24}$ Goodman, p. 106
}

Brasiliana - Journal for Brazilian Studies. Vol. 1, n.1 (Sept. 2012). ISSN 2245-4373. 
acima propostos, obedecendo à estrutura de reconhecimento ontológico entre um e outra culturas.

\section{Conclusão}

Tentamos, neste artigo, abraçar os principais aspectos ou alguns dos problemas essenciais acerca dos chamados "Estudos Brasileiros", ao tentar identificá-los, relativizálos e aplicá-los no contexto nacional e internacional, primeiramente no que concerne os estudos feitos sobre o Brasil, de maneira geral, e, finalmente, sua recepção literária na França, em particular.

Tais problemas de ordem ontológica, epistemológica e pragmática nos fazem pensar no trabalho, constante, de transformação ideológia e conceitual a que estamos habituados quando tentamos estudar a cultura nacional, londe da origem, e perto de outros pesquisadores que fazem, aproxidamente, o mesmo percurso científico, quando o foco pragmático é, ainda, o desconhecido.

Essa "aproximação" ideológica desenhada na situação inexorável comum entre aqueles que pesquisam a cultura brasileira no exterior, i.e., daqueles que se vêem "obrigados" ao diálogo geral produz a necessidade epistêmica e empírica da evolução das relações entres as áreas humanistas na perspectiva do trabalho "polivalente" da pesquisa acadêmica.

Seria, talvez, interessante pensar na dinâmica interna, nas motivações idiossincráticas das diversas áreas dos Estudos Brasileiros e imaginar, com efeito, uma situação epistemológica em que a troca intelectual seria mais uma identidade do que uma diferença. 


\section{Bibliografia}

Bachelard, G. La formation de l'esprit scientifique. Paris: Vrin, 1938.

Barbaras, Renaud. Le désir de la distance. Introduction à une phénoménologie de la perception. Paris: Vrin, 1999.

Bergson, Henri. Matière et Mémoire, Paris: PUF, 1965; e La pensée et le mouvant. Paris: Les Presses universitaires de France, PUF, 1969.

La perception du changement. Paris: PUF, 2011.

. Sur le pragmatisme de William James. Paris: PUF, 2011.

Deleuze, G. Différence et Répétition, Paris: PUF, 1969.

Glissant, É. Pays rêvé, pays réel. Paris: Gallimard, 2000.

Poétique de la relation. (Poétique III) Paris: Gallimard, 1990

Goodman, Nelson. Ways of wordlmaking (Manière de faire les mondes). Trad. MarieDominique Polelard. Paris: Folio Essais.

. Langages de l'art. Traduit par Jacques Morizot. Paris: Hachette, Littératures. 1990.

Guillermit, Louis. Leçons sur la «Critique de la raison pure» de Kant, Paris, Vrin, 2008

Heidsiek, François. Henri Bergson et la notion d'espace. Paris: L'Harmattan. 3è édition, 2010.

Jankelevitch, Vladimir. Le Je-ne-sais-quoi et le presque-rien, Paris, PUF.

Levinas, Emmanuel. Totalité et infini. Essais sur l'extériorité. Nijhoff, La Haye, 1961. . En découvrant l'existence avec Husserl et Heidegger. Paris: Vrin, 2001.

Locke, Essai concernant l'entendement humain, Paris: Vrin, 1989.

Brasiliana - Journal for Brazilian Studies. Vol. 1, n.1 (Sept. 2012). ISSN 2245-4373. 
Rambourg, Márcia Marques. Por uma discussão ontológica e epistemológica dos ditos "Estudos Brasileiros" e algumas de suas consequências empíricas na França.

Merleau-Pontu, Maurice. Phénoménologie de la perception. Paris: «Tel» Gallimard, 1945.

Morizot, J. La philosophie de l'art de Nelson Goodman. Paris: Ed. Jacqueline Chambon. 1996.

Spinoza, B. Éthique. Introduction, traduction et commentaires de Robert Mishrabi. Paris: Éclats EDS, 2005.

Wahl, Jean André. Vers le concret, Vrin, 1932; rééd. Avant propos de Mathias Girel, Paris: Vrin. 